\title{
PLEA BARGAINING NOS ESTADOS UNIDOS DA AMÉRICA E OS JUIZADOS ESPECIAIS CRIMINAIS NO BRASIL: UMA ANÁLISE DE DIREITO ESTRANGEIRO.
}

Henrique Ribeiro Cardoso ${ }^{1}$

Eliezer Siqueira de Sousa Júnior²

\section{RESUMO}

O uso inadequado do termo "direito comparado" retira desta área do direito a seriedade que tem. Analisar aspectos jurídicos de outros países nem sempre leva a um estudo técnico de direito comparado. Diferenciar direito comparado da noção de direito estrangeiro é fundamental para o presente trabalho, que se debruça sobre o estudo do "plea bargaining", instituto do direito norte-americano, que se revela como método de resolução de casos criminais, e seus correlatos dentro do direito brasileiro, chegando ainda a uma reflexão sobre a existência, ou não, no Brasil, de um verdadeiro procedimento de acordo entre as partes no direito brasileiro.

PALAVRAS-CHAVE: direito comparado, direito estrangeiro, "plea bargaining", acordos criminais, resolução de conflitos.

\section{PLEA BARGAINING IN THE UNITED STATES OF AMERICA AND SPECIAL CRIMINAL COURTS IN BRAZIL: AN ANALYSIS OF FOREIGN LAW.}

\section{ABSTRACT}

The misuse of the term "comparative law" removes from this area of law its seriousness. Analyzing legal aspects of other countries does not always lead to a technical study of

1 Doutor em Direito, Estado e Cidadania (UGF/Rio), com Pós-doutorado em Democracia e Direitos Humanos (IGC - Universidade de Coimbra); Pesquisador em Estágio Pós-doutoral em Direitos Humanos e Desenvolvimento (PPGCJ/UFPB); Mestre em Direito, Estado e Cidadania (UGF/Rio); Professor do Programa de Pós-graduação da Universidade Federal de Sergipe (PRODIR/UFS) e do Programa de Pósgraduação da Universidade Tiradentes (PPGD/UNIT); Promotor de Justiça da Primeira Curadoria da Fazenda Pública em Sergipe (MPSE); Membro da Academia Sergipana de Letras Jurídicas (ASLJ).

2 Mestrando em Constitucionalização do Direito pelo Programa de Pós-graduação Direito da Universidade Federal de Sergipe (UFS). Juiz de Direito do Tribunal de Justiça do Estado de Sergipe (TJSE). 
comparative law. Differentiating comparative law from the notion of foreign law is fundamental to the present work, which focuses on the study of plea bargaining, an institute of American law, which is revealed as a method of solving criminal cases, and its correlates Within the Brazilian law, coming to a reflection on the existence or not, in Brazil, of a true agreement between the parties in Brazilian law.

KEYWORDS: comparative law, foreign law, plea bargaining, criminal agreements, dispute resolution.

\section{Introdução}

A globalização causou a multiplicação de relações entre os povos. O "mundo sem fronteiras" transformou as relações humanas, inclusive as jurídicas. Neste contexto, uma necessidade premente desta "aldeia global" é a análise dos ordenamentos jurídicos de outros países como forma de entender e aprimorar seus sistemas.

Além do crescimento dos ramos de direito que se debruçam no trato das relações jurídicas entre os povos, mais notadamente o direito internacional público e privado, surge a necessidade de se desenvolver uma técnica capaz de analisar sistemas jurídicos de diferentes países, verificando semelhanças e diferenças, com o escopo de se compreender os povos e melhorar as relações da comunidade internacional.

Assim, o chamado direito comparado ${ }^{3}$ vem cada vez mais se sedimentando como necessidade essencial da comunidade jurídica internacional, e não só dela ${ }^{4}$, tanto para estreitar laços entre os países quanto para o próprio desenvolvimento do direito interno.

Neste contexto, o presente artigo propõe uma breve reflexão sobre o direito comparado, a diferença com o chamado direito estrangeiro, a internalização dos institutos jurídicos pertencentes a outros países no direito interno, passando a uma análise do instituto do plea bargaining, oriundo do direito norte-americano, sua influência no direito penal (material e

3 Utilizaremos a consagrada expressão "direito comparado", sem deixar de salientar a existência de fortes críticas a esta nomenclatura, preferindo alguns o termo "comparação de direito" (do alemão Rechtsvergleichung), "comparação jurídica", expressão dada por Alberto Tripiccione, ou ainda "método de interpretação comparada". Sobre o assunto, ver PESSOA, 2009, p. 28; DUARTE, 2006, p. 770; SIQUEIRA, 2013, p. 1.

4 Por exemplo, Max Weber, reconhecido como o pai da sociologia, debruçou-se profundamente na análise dos direitos orientais e teológicos para construir sua tipologia sociológica com o intuito de compreender a racionalidade do mundo jurídico ocidental (GODOY, 2008, p. 8). 
processual) brasileiro, e finalmente uma reflexão acerca da real existência em nosso país deste instituto originado no direito norte-americano.

\section{O Direito comparado e o Direito Estrangeiro}

Chama-se de direito comparado a comparação de diversas ordens jurídicas (DUARTE, op. cit., p. 770), "um específico objeto do indagar jurídico e que tem por missão instrumentalizar o funcionamento do ordenamento" (MENDONÇA, 2001, p. 1).

Com origem que remonta à Grécia e Roma antigas, Marc Ancel, grande estudioso do comparativismo, afirma que foi Charles Louis de Secondat, o Barão de Montesquieu, o primeiro dos comparativistas, por lançar mão de legislações de outros países para escrever seu famoso “O Espírito das Leis”, em 1748 (PESSOA, 2009, p. 13-14).

No entanto, quem primeiro utilizou a expressão "direito comparado" foi René David, em sua obra "Les Grands Sistèmes de Droit Contemporains", em 1964, muito embora tenha empregado em outro sentido: "para distinguir a comparação feita entre ordens jurídicas da mesma família da feita entre ordens jurídicas de famílias diversas" (DUARTE, 2006, p. 772). Tal situação levou Léontin-Jean Constantinesco a reivindicar o ineditismo na utilização da expressão em seu sentido que posteriormente se popularizou (DUARTE, idem).

Sem pretender, necessariamente, a uma unificação mundial da comunidade jurídica ${ }^{5}$, o direito comparado se revela como elemento indispensável na análise das convergências e divergências entre sistemas de direito (DELMAS-MARTY, 2003, P.104-105), como forma de integrar e aprimorar o direito interno e as relações de direito internacional.

Conforme Willis Santiago Guerra Filho, o direito comparado possui três sentidos principais: um tido por larguíssimo, se relaciona a referências à literatura estrangeira nos trabalhos jurídicos pátrios, sem qualquer preocupação metodológica. Em um segundo sentido, amplo, é empregado para designar o estudo comparativo que analisa institutos de países pertencentes à mesma família jurídica. E por fim, em sentido estrito, debruça-se sobre o sistema jurídico de países de famílias distintas (PESSOA, op. cit., p. 29).

Sendo uma disciplina metodológica, o direito comparado se revela, ao mesmo tempo,

5 Há de se salientar que muitos autores conceberam um "direito comum da comunidade civilizada", como Raymond Saleiles e o grande jurista chinês Shen Jiaben (DELMAS-MARTY, 2003, p. 102-103). 
como ciência ${ }^{6}$ e como método ${ }^{7}$. Como ciência, revela-se como um processo de investigação voltado para a pesquisa, que possui como objeto o direito de outros países e pressuposto nos problemas jurídicos, que acarreta na formulação de um problema, constituindo-se em verdadeira questão científica (PESSOA, op. cit., p. 36-37).

Como método, o direito comparado parte de um conjunto de procedimentos que visam alcançar determinado resultado, dentro de princípios preestabelecidos (COUTINHO, 2003, p 37), revelando-se em uma técnica particular de pesquisa, que comumente se afere dentro de uma base empírica, notadamente a experiência jurídica. (PESSOA, op. cit., p. 37).

Já o direito estrangeiro seria, ordinariamente, sinônimo de lei estrangeira. O professor Osiris Rocha, em artigo dos anos 60, já dizia: "porque aplicar a lei estrangeira? Ou, que motivo autorizaria ao juiz local seguir o critério estrangeiro?” (ROCHA, 1964, p. 67).

Classicamente, no ramo do direito internacional privado, o direito estrangeiro é reputado como uma regra de resolução de conflito entre norma nacional e norma alienígena, com o escopo de se determinar qual das normas será aplicável (BAPTISTA, 1999, p. 267).

Entretanto, o que se reputa direito estrangeiro, dentro de uma análise de sua relação com o denominado direito comparado, diz respeito a análises e estudos das fontes jurídicas estrangeiras, aproximando-se do conceito larguíssimo apresentado por Guerra Filho, havendo verdadeira simbiose, na medida em que "o direito comparado está na dependência de estudos de direito estrangeiro e que o direito estrangeiro é a matéria-prima do direito comparado" (PESSOA, op. cit., p. 29, itálico no original).

Sendo o direito estrangeiro, neste sentido, objeto do direito comparado, faz aquele parte do processo de conhecimento a ser desvendado por este, que possui outros elementos a serem enfrentados. Júlio Siqueira, citando Héctor Fix-Zamudio, afirma que, em uma análise perfunctória, o direito comparado pode ser dividido em três elementos básicos: a exposição do direito estrangeiro, como requisito prévio necessário para qualquer pré-compreensão do sistema alienígena; a análise dos problemas metodológicos da comparação jurídica (direito comparado em sentido estrito); e o estudo das disciplinas comparativas de caráter específico (SIQUEIRA, 2013, p. 2-3).

6 Ciência: Conhecimento que inclua, em qualquer forma ou medida, uma garantia da própria validade. Essa garantia pode consistir: $1^{\mathrm{a}}$ na demonstração; $2^{a}$ na descrição; $3^{\mathrm{a}}$ na corrigibilidade (ABBAGNANO, 1998, p. $145)$.

7 O termo "método" possui dois sentidos básicos: um amplo, que se refere a qualquer pesquisa ou orientação de pesquisa; outro estrito, que diz respeito a um conjunto de técnicas e processos específicos voltados a pesquisa (ABBAGNANO, op. cit., p.682). 
O direito comparado, portanto, não se confunde com direito estrangeiro por não se tratar de mera referência ou conhecimento dos direitos de outros países. Possui um objeto próprio (estudo de, ao menos, duas ordens jurídicas), um método próprio (o comparativo) e as suas conclusões, denominada de síntese comparativa (CARVALHO, 2008, p. 144).

Desta forma, passaremos a nos debruçar especificamente sobre o direito estrangeiro para estabelecer suas influências sobre o direito brasileiro, prescindindo de uma análise mais aprofundada proporcionada pelo método de interpretação comparada, como medida mais adequada à análise que aqui pretende se estabelecer.

\section{Internalização do Direito estrangeiro no Direito pátrio}

Vários são os fenômenos que levam à aplicação do direito estrangeiro (não-nacional) dentro de um país: tratados, convenções, protocolos de intenções, dentre outros. Esses procedimentos são voltados à prática de um direito internacional que integra as intenções dos povos e que demandam uma análise específica, que transcende o objetivo do presente artigo.

O que se destaca nesta denominada internalização do direito estrangeiro é a sua influência em relação ao direito nacional, numa relação de mão dupla, pois cada país contribui, à sua maneira, para o aperfeiçoamento dos institutos jurídicos no plano global.

Costuma-se dizer que o direito estrangeiro serve, numa primeira análise, como fonte de inspiração do direito nacional. Ou seja, dentro do cenário internacional, seus diferentes atores partem para um processo de diálogo, estabelecendo um "processo transjudicial internacional", buscando integrar, interpretar e internalizar as normas estrangeiras no campo doméstico (VARELLA, 2012, p. 109).

Para tanto, serve o direito estrangeiro tanto de elemento na busca de soluções jurídicas, através de regras e princípios do direito internacional privado, complementando o direito nacional, quanto para um intercruzamento normativo, resultado de um processo crescente em uma procura por "soluções jurídicas para problemas comuns" (VARELLA, op. cit., p. 116).

Como elemento de resolução de questões através de regras de direito internacional privado para complementação do direito pátrio, o direito estrangeiro se revela como uma prática internacional de jurisdição usual. $\mathrm{O}$ direito internacional privado possui regras 
próprias, metodologia ${ }^{8}$ própria, resultado de anos de dedicação de diversos autores, o que transcende o intento deste artigo.

Entretanto, é significativo o processo de internalização do direito estrangeiro no direito interno como fenômeno decorrente do desenvolvimento de soluções para problemas jurídicos comuns que se relacionam com a comunidade jurídica internacional.

Este intercruzamento normativo se aprofunda dentro de um contexto de globalização, em que os problemas dos países passam a ser mais comuns do que outrora, na medida em que vários temas adquirem repercussão mundial, como a corrupção e o combate da criminalidade, demandando soluções mais alinhadas pelos países com o mesmo tipo de preocupação (DELMAS-MARTY, 2003, p. 107).

O intercruzamento normativo se revela como relação entre os direitos estrangeiro e nacional a partir de envolvimento mútuo entre os Estados, com tratamentos jurídicos comuns de forma voluntária ou acordada, sem modificar o cenário normativo interno, causando alterações superficiais dos ordenamentos jurídicos (VARELLA, op. cit., p. 120-121).

Desta forma, os processos de internalização de direitos, como fenômenos concomitantes, progressivos, assimétrico e variáveis conforme matéria, tempo e espaço, revelam-se imprescindíveis para o aprimoramento do direito interno, para a modificação da ideia mundial e aproximação dos povos pela busca de soluções jurídicas para problemas comuns.

\section{Acordos criminais nos Estados Unidos da América - PLEA BARGAINING}

O plea bargaining é um acordo obtido entre a acusação e a defesa no qual o acusado declara sua culpa em troca de uma sentença mais branda, evitando ainda um processo mais demorado (GIVATI, 2011, p. 2) ${ }^{9}$.

O plea bargaining consiste em um procedimento de negociação entre as partes do processo criminal, na qual o acusado confessa a culpa (guilty plea ou plea of guilty) ou declara que não deseja o prosseguimento do processo (declaração de nolo contendere) em troca de uma pena mais branda, fora o fato de encerrar o processo mais rapidamente e também

8 O termo "metodologia" foi aqui empregado significando a "lógica ou parte da lógica que estuda os métodos" (ABBAGNANO, 1998, p. 683).

9 Tradução livre do autor. No original: "is an agreement between the prosecution and the defense whereby the defendant pleads guilty in exchange for a more lenient sentence, and a full trial is avoided". 
evitar mais custos tanto para o Estado quanto para o acusado.

Integrante do common law, o direito norte-americano não tem preocupação em estabelecer dogmas ou princípios como no sistema do civil law, aplicando o direito através de casos anteriores. Ou seja, é o caso particular que cria a norma geral, e não o contrário, baseado no respeito a uma decisão anterior, o denominado "precedent".

No civil law, as normas nascem de comandos abstratos, que regulam as relações cotidianas, o que reforça o estudo aprofundado das leis e a elaboração de uma profunda abordagem teórica dos institutos jurídicos, reforçando uma cultura dogmática neste sistema romano-germânico.

Já no common law, a norma surge da solução judicial dada a um conflito concreto de interesses. O sistema de precedentes se revela como a análise minuciosa de casos anteriores para, após esta verdadeira "pesquisa", aplicar a decisão anterior que melhor se adequa ao caso atual (MARTINS; SIQUEIRA, 2016, p. 303-304).

É neste contexto que se insere o instituto do plea bargaining: baseado no convencionalismo, reflexo da cultura jurídica norte-americana, que nunca se ocupou em teorizar o exercício ao direito de ação, o direito penal obedece a razões políticas, promovendo, de um lado, uma gradual despenalização prática de condutas socialmente irrelevantes, e de outro a concentração de esforços em crimes de maior repercussão, onde o acordo entre as partes permite uma aplicação de pena mais adequada ao acusado (SANTOS, 2016, p. 31).

O procedimento do plea bargaining no Sistema Federal dos Estados Unidos da América está previsto no "Federal Rules of Criminal Procedure, Rule 11 - Pleas"10, ressaltando que aproximadamente dois terços dos Estados seguem estas regras ${ }^{11}$, ainda que possuam autonomia para legislarem sobre matéria penal (MESSITTE, 2010, p. 5).

Em geral, cabe ao indivíduo que recebe uma imputação acusatória três opções: ele pode se declarar culpado de forma expressa (plea of guilty ou guilty plea), pode afirmar que não quer contestar a ação penal, mas sem admitir sua responsabilidade (plea of nolo contendere), ou se declarar inocente, ou "não culpado" (plea of not guilty), restando esta declaração presumida caso o acusado se quede em silêncio - Rule 11(a) (1) e (4) ${ }^{12}$.

10 Disponível em <https://www.law.cornell.edu/rules/frcrmp/rule_11>.

11 O Estado do Alasca e a cidade de Filadelfia, no Estado da Pensilvânia, proíbem expressamente estes acordos, ao passo que a cidade de El Paso, no Estado do Texas, não o permite para o caso de crimes graves (MESSITTE, 2010, p. 9).

12 “(1) In General. A defendant may plead not guilty, guilty, or (with the court's consent) nolo contendere. (...) 
Ao se declarar culpado (plea of guilty), o acusado assume todas as consequências de uma condenação criminal, incluindo a possibilidade de ser acionado pela vítima judicialmente na seara cível, pois tal sentença se constitui, de plano, em título executivo judicial.

Pode ainda efetuar uma declaração de culpa condicionada (conditional plea - Rule 11(a) (2)), na qual o acusado não contesta a prática do fato a si imputado pela acusação (factually guilty), mas se insurge contra a “not legally guilty”, isto é, contesta a legalidade da persecução. Isto garante ao acusado o direito de apelar tão somente a questões processuais quando tenha seus pedidos indeferidos pelo juízo do julgamento (SANTOS, 2016, p. 33-34).

Quando o acusado apresenta uma "plea of nolo contendere" - Rules 11(a) (3) - não admite a culpa como apresentada pela acusação: simplesmente escolhe não contestar o que lhe foi imputado. A consequência mais marcante desta opção é a não constituição, de plano, de título executivo judicial em desfavor do acusado, tratando-se de sentença penal condenatória desprovida de consequências na órbita civil (SANTOS, 2016, p. 34-35).

Note-se que, se o acusado optar por se declarar culpado ou optar por não impugnar a acusação, o processo tenderá a um desfecho mais rápido, o que acarreta, também, em economia processual. Se, por outro lado, optar por se declarar inocente, o processo segue para um julgamento, que deve ser rápido e público ${ }^{13}$, a princípio efetuado pelo Grande Júri ${ }^{14}$.

$\mathrm{Se}$ as partes pretenderem entabular um acordo, dão início ao denominado "Plea Agreement Procedure" (Procedimento de acordo), disciplinado na Rules 11 (c) (1). O procedimento deve ser totalmente gravado ("recording the proceedings" - Rules 11(g)),para comprovar os dois requisitos subjetivos necessários à admissão do acordo: a voluntariedade e a inteligência da declaração do acusado.

A voluntariedade é prevista na Rules 11(b) (2), onde a Corte de Justiça só pode aceitar uma "plea of guilty" ou uma declaração de "nolo contendere" após se dirigir pessoalmente ao acusado e verificar que o pedido não resultou de coação física, ameaças ou promessas juridicamente inviáveis ${ }^{15}$.

Já a inteligência se extrai do item (b) (1) da Rules 11, onde há extenso rol de medidas a

(4) Failure to Enter a Plea. If a defendant refuses to enter a plea or if a defendant organization fails to appear, the court must enter a plea of not guilty.".

13 A Emenda VI da Constituição Americana estabelece que: "In all criminal prosecutions, the accused shall enjoy the right to a speedy and public trial (...)".

14 Rule 11(b) (1) (c).

15 No original: “(2) Ensuring That a Plea Is Voluntary. Before accepting a plea of guilty or nolo contendere, the court must address the defendant personally in open court and determine that the plea is voluntary and did not result from force, threats, or promises (other than promises in a plea agreement)." 
serem tomadas pelo Juízo para averiguar se o acusado possui consciência e pleno entendimento sobre a declaração que está a fazer perante o Tribunal ${ }^{16}$.

Tudo isto para garantir ao Tribunal que o Acusado possui a exata compreensão do que significa a sua declaração e as suas consequências. A Suprema Corte Norte Americana já sedimentou o entendimento de que o grau de discernimento exigível para se admitir um "plea of guilty" ou uma declaração de "nolo contendere" é o mesmo necessário para que o acusado seja submetido a um julgamento formal, apto a aplicação de uma sanção penal, uma vez que estas declarações se revelam em verdadeiras sentenças penais condenatórias (Precedente Godinez v. Moran, de 1993) $)^{17}$.

Após observar que a declaração é voluntária, consciente e livre, o Juiz passa a verificar se o acusado se encontra orientado no tempo e no espaço, indagando sobre suas qualificações pessoais, se faz uso de alguma medicação que possa afetar a sua compreensão e se é atendido regularmente por algum profissional da área de saúde mental, por exemplo. Pergunta também se ele foi de alguma forma coagido, pressionado ou se alguém lhe prometeu algum benefício impróprio para que o mesmo declare a sua culpa (MESSITTE, 2010, p. 6-7).

Após, estando o Juiz convencido de que a declaração é legalmente válida, passa o Juiz a averiguar se existe no processo um mínimo probatório apto (Rules 11(b) (3)) ${ }^{18}$. Isto porque a declaração, seja uma plea of guilty ou uma nolo contendere, tem a natureza jurídica de sentença penal condenatória, não carecendo de suporte fático mínimo para a sua admissão. Entendendo o Juiz que não há elementos mínimos necessários para aceitar a declaração, rejeitará o acordo firmado pelas partes, exercendo verdadeira fiscalização judicial das evidências.

\section{Acordos entre as partes no Direito penal brasileiro}

O ordenamento jurídico brasileiro segue o sistema denominado de Civil Law, de

16 A lista é extensa e possui 15 itens, dos quais podemos destacar os seguintes esclarecimentos a serem feitos pelo Juiz: o direito do Estado de usar a declaração feita pelo acusado em eventual processo de perjúrio ou falso testemunho; o direito a um julgamento pelo júri; o direito a ser representado por um advogado perante o Tribunal; o direito de confrontar e contra argumentar provas adversas; a natureza do encargo que o acusado pleiteia; os termos de qualquer disposição em que as partes renunciem ao direito de recorrer, dentre outros.

17 Disponível em: <https://web.archive.org/web/20080514024101/http://bama.ua.edu:80/ jhooper/godinez.html>.

18 No original: "(3) Determining the Factual Basis for a Plea. Before entering judgment on a guilty plea, the court must determine that there is a factual basis for the plea". 
tradição romano-germânica. Este modelo se baseia na supremacia do texto constitucional e seu consequente controle de constitucionalidade, na dicotomia estabelecida entre o direito público e privado, na valorização da lei escrita e na participação do Poder Judiciário atrelada à interpretação e aplicação dos diplomas legais (GORDILHO, 2009, p. 9423-9424).

Diferentemente do sistema do Common Law, onde os precedentes, ao lado dos costumes, se demonstram como matéria-prima na confecção e aplicação do direito, que resta criado pelo próprio Judiciário, no nosso sistema de tradição romano-germânica a principal fonte jurídica repousa sobre a lei, produto do Poder Legislativo.

Assim, dentro de um modelo de respeito às normas, firmado pela obediência às leis, que só são afastadas ante, por exemplo, a revogação ou a declaração de inconstitucionalidade, o Judiciário, tradicionalmente, pouca chance tem de inovar na aplicação das normas.

Tem-se, no Brasil, como marco inicial para a negociação entre as partes no processo penal o advento da Constituição de 1988 que, em seu art. 98, I, estabeleceu que os entes federativos deveriam criar juizados especiais com competência para a "conciliação, $o$ julgamento e a execução de (...) infrações penais de menor potencial ofensivo, mediante os procedimentos oral e sumariíssimo, permitidos, nas hipóteses previstas em lei, a transação (...)" (grifo nosso).

Antes, porém, da implantação dos juizados especiais, cíveis e criminais, a Lei de Crimes Hediondos - Lei $\mathrm{n}^{\circ}$ 8.072, de 25 de julho de 1990 - modificou, em seu art. $7^{\circ}$, a redação do art. 159 do Código Penal, prevendo uma causa especial de diminuição de pena para favorecer o autor ou partícipe de crime de extorsão mediante sequestro, executado em quadrilha ou bando (requisito este posteriormente dispensado pela Lei 9.269/1996), que fornecesse elementos que ajudassem na libertação de eventuais vítimas, o que foi uma semente neste modelo de participação mais efetiva das partes na resolução do processo penal, onde o acusado, por um lado, colabora com a resolução de um crime, e por outro recebe uma redução proporcional na pena, previamente estabelecida na lei.

Entretanto, a sistematização do acordo a ser estabelecido entre as partes no processo penal ocorreu com o advento da lei 9.099, de 26 de setembro do 1995, que instituiu os juizados especiais cíveis e criminais, estes com competência para a conciliação, julgamento e a execução das infrações penais com pena máxima cominada pela lei não superior a dois anos, critério este estabelecido para se definir o conceito constitucional de "menor potencial ofensivo" (arts. 60 e 61). 
Com a instituição deste microssistema, e fundado numa nova ideia de se dar celeridade e eficiência aos processos de menor complexidade, a Lei dos Juizados Especiais passou a contar com diversos mecanismos para solucionar qualitativamente as suas demandas. Desta feita, passou a contar com poderosa ferramenta de trabalho para alcançar os seus objetivos: o consenso.

Assim, instrumentos como a composição civil (art. 74), a transação penal (art. 76) e a suspensão condicional do processo (art. 89, todos da Lei 9.099/95) passaram a fazer parte do cotidiano forense, mudando a mentalidade da ação penal obrigatória, que muitas vezes prendia as partes a um processo sem nenhuma relevância prática e social.

Se anteriormente, o ato de negociação entre as partes era visto como uma conduta ilegal e imprópria, mesmo nos casos em que o acusado admitia sua culpa, havendo necessidade de transcorrer todas as etapas do processo previstas no processo, amarrado a uma faceta formal do devido processo legal, tudo em busca de uma "verdade real" inegociável, a partir da lei de juizados especiais passou-se a prever o acordo entre as partes como solução para o conflito penal, criando um senso de responsabilidade pública e processual nos participantes do processo.

Como mecanismo apto a dirimir questões inclusive extrapenais, a lei passou a prever a composição civil dos danos, o que era impensável antes de 1995, como forma de extinção do processo penal. Realizável perante conciliador, juiz leigo ou juiz togado, tal acordo civil estabelecido entre as partes no procedimento sumariíssimo criminal serve para extinguir a ação penal, após a homologação judicial mediante sentença irrecorrível, com natureza de título executivo judicial a ser acionado no juízo competente caso haja descumprimento do acordo (art. 74, da Lei 9.099/95), não alterando os efeitos criminais se houver inadimplemento.

Ultrapassada, ou não sendo possível a composição civil, a lei dos juizados apresenta outro instituto negocial, a transação penal. Neste, o membro do Ministério Público, observado o cumprimento dos requisitos e não havendo impedimento para a proposta, conforme disposto no art. $76, \S 2^{\circ}$ da mencionada lei, propõe a aplicação imediata de pena restritiva de direito ou multa ao acusado.

Em tal situação, a aceitação do suposto autor dos fatos não produz os mesmos efeitos de uma sentença penal condenatória, não induz reincidência, não gera anotação em certidão de antecedentes criminais e nem faz coisa julgada material na esfera cível (GIACOMOLLI, 
VASCONCELOS, 2015, p. 1115-1116), ficando tão-somente impedido de lançar mão do mesmo benefício pelo prazo de cinco anos (art. 76, § 2º II, da Lei 9.099/95).

Ainda, traz a lei dos juizados especiais outro instituto a ser aplicado, inclusive, em processos que não são de sua competência, a suspensão condicional do processo, onde, em mais uma hipótese de consenso criminal, pode-se suspender o regular andamento e a prescrição do processo por um período de dois a quatro anos, atendidos outros requisitos (art. 89).

\section{Semelhanças e diferenças entre os acordos criminais nos Estados Unidos da América e no Brasil}

Nota-se que, diante do fenômeno da globalização, os sistemas jurídicos revelam dificuldades em seguir o rumo dinâmico da sociedade. Desta feita, como decorrência do método do direito comparado, os países integrantes dos sistemas do Common Law e do Civil Law passaram a estabelecer estudos para compreenderem uns aos outros, acarretando em aproximação de seus institutos para encontrar soluções à criminalidade crescente e progressiva.

Os institutos consensuais previstos na lei dos juizados especiais possuem relação de proximidade com os elementos do plea bargaining norte-americano, na medida em que em ambos o protagonismo judicial dá lugar ao entendimento das partes, que se demonstram mais aptas a vindicar seus interesses, o que reforça a ideia de um sistema penal puramente acusatório. Outra semelhança reside no fato de que o acusado, nos dois sistemas, tem a possibilidade de se submeter a uma pena mais branda ou, ainda, evitar o prosseguimento de uma ação penal que possa lhe trazer maiores transtornos.

Em outra quadra, as modalidades de consenso previstas na lei dos juizados especiais se diferem dos institutos do plea of guilty e do nolo contendere, na medida em que, nos institutos estrangeiros, os acordos são verdadeiras sentenças penais condenatórias, tendo entre si diferenças tão-somente na esfera cível, ao passo que no direito pátrio os institutos citados não produzem os mesmos efeitos de uma sentença penal condenatória (GIACOMOLLI, VASCONCELOS, 2015, p. 1115-1116), causando apenas um impedimento ao acusado em ser beneficiado novamente pelo instituto pelo prazo de cinco anos.

Outra diferença destacada reside no fato de que no plea bargaining norte-americano o 
exercício da ação penal é baseado na absoluta discricionariedade dos órgãos encarregados pela acusação (SANTOS, 2016, p. 33) que, segundo MESSITTE, eram compostos, em 2010, por 94 escritórios de advocacia espalhados pelos Estados Unidos da América (op. cit., p. 2). Por conseguinte, a acusação não é obrigada estabelecer qualquer acordo com a defesa do acusado, diferentemente do caso brasileiro, onde preenchidos os requisitos contidos na lei, tem o acusado o direito subjetivo de negociar com o Ministério Público (GIACOMOLLI, VASCONCELOS, 2015, p. 1116).

\section{Existe o plea barbaining no Brasil?}

Diante da análise comparativa entre os institutos de consenso criminais dos países elencados, chega-se a conclusão de que, muito embora os institutos de acordo no processo criminal previstos na Lei 9.099/95 tenham clara inspiração no modelo norte-americano, não se pode afirmar que o Brasil adotou plenamente o modelo do plea bargaining.

Inicialmente porque, muito embora haja semelhanças, vê-se que, no sistema brasileiro, a acusação é obrigada a fazer uma proposta ao acusado, quando este preenche os requisitos legais, por ser um direito subjetivo seu, demonstrando claramente seu traço ligado à Civil Law, instituto que sempre lança mão da lei para estabelecer requisitos a serem criteriosamente observados pelos órgãos componentes do sistema judicial.

Ademais, as partes ainda dependem de participação do Poder Judiciário para estabelecerem acordos, ainda que preliminares, não havendo previsão legal para a ocorrência de audiências entre as partes sem a participação de algum integrante do sistema judicial, seja conciliador, juiz leigo ou magistrado togado, diferentemente do modelo estabelecido pela Federal Rules of Criminal Procedure 11, que inclusive impede a participação do Tribunal nessas discussões - (c) (1), o que revela a disposição que as partes possuem para dialogarem sobre o processo.

Muito embora existam outros modelos atualmente em uso no Brasil, como o estabelecido na Lei de Organização Criminosa (Lei 12.850/2013), e projetos de lei para se aplicá-lo, como o PL 8045/2010 - projeto de lei para criar o Novo Código de Processo Penal, em trâmite na Câmara dos Deputados, não temos, entre nós, o plea bargaining nos moldes norte-americanos, no que cabe ainda profunda reflexão sobre suas consequências, caso seja adotado integralmente. 


\section{Conclusão}

À guisa de entendimento, vê-se que o direito comparado é método cientifico extremamente comprometido com a análise de diversos modelos jurídicos mundiais, o que se revela cada vez mais necessário ante a globalização, onde a comunidade jurídica mundial lança mão de institutos jurídicos de seus componentes para buscar respostas aos problemas.

Neste contexto, os sistemas do Common Law e Civil Law realizam movimento de aproximação adotando uns dos outros expedientes para resolver suas deficiências, a partir de uma análise científica de suas estruturas.

Assim, no caso brasileiro, buscou-se uma aproximação do modelo norte-americano do plea bargaining, aplicando-o aos fatos de menor ou médio potencial ofensivo, como forma de garantir a eficiência e celeridade destes processos.

Todavia, tal aproximação não se revelou completa, haja vista a diferença considerável que ainda reside entre o modelo adotado pelo Brasil e o que é praticado nos Estados Unidos, o que demonstra que toda a aproximação das legislações estrangeiras demanda tempo para sedimentar em uma nova realidade interna.

Por fim, cremos que, no mínimo, os institutos de acordo em processos criminais poderiam ser adotados entre nós aos crimes cuja pena máxima estabelecida em lei fosse de até quatro anos, uma vez que são delitos hoje que não recebem pena de prisão.

JESÚS-MARIA SILVA SÁNCHEZ (2002, p. 146-147) assim assevera:

\footnotetext{
"Para resumir, pode ser dito que, na medida em que a sanção seja a de prisão, uma pura consideração de proporcionalidade requereria que a conduta assim sancionada tivesse uma significativa repercussão em termos de afetação ou lesividade individual; ao mesmo tempo, seria procedente - exatamente pelo que foi aludido manter um claro sistema de imputação individual (pessoal). Mas, vejamos, na medida em que a sanção não seja a de prisão, mas privativa de direitos ou pecuniária, parece que não teria que exigir tão estrita afetação pessoal; e a imputação tampouco teria que ser tão abertamente pessoal. A ausência de penas 'corporais' permitiria flexibilizar o modelo de imputação". (Grifo nosso)
}

Tal assertiva se baseia nas mudanças do Código Penal, que já em 1998, com a Lei 9.714, passou a adotar um sistema de substituição de penas privativas de liberdade por 
restritivas de direito para crimes cuja pena não seja superior a quatro anos (art. 44, I, do Código Penal), e do Código de Processo Penal, pela Lei 12.403/2011, que passou a não admitir, como regra, a prisão preventiva para crimes dolosos punidos com pena privativa de liberdade máxima de até quatro anos (art. 313, I, a contrário senso), o que justificaria a ampliação de negócio jurídico penal a estes crimes.

\section{Referências}

ABBAGNANO, Nicola. Dicionário de filosofia. Tradução Alfredo Bosi et alli. São Paulo. Martins Fontes. 1998.

BAPTISTA, Luiz Olavo. Aplicação do direito estrangeiro pelo juiz brasileiro. Revista de informação legislativa: v. 36, n. 142, p. 267-277 (abr./jun. 1999). Senado Federal. Disponível em <http://www2.senado.leg.br/bdsf/handle/id/490>. Acesso em 12/06/2017.

BRASIL. Constituição (1988). Constituição da República Federativa do Brasil. Brasília, DF. Disponível em <http://www.planalto.gov.br/ccivil_03/constituicao/constituicaocompilado.htm>. Acesso em 23/07/2017.

CARVALHO, Welinton. Direito comparado: Método ou ciência? Revista de informação legislativa: v. 45, n. 1180, p. 139-145 (out./dez. 2008). Senado Federal. Disponível em <https://www2.senado.leg.br/bdsf/bitstream/handle/id/176559/000848846.pdf?sequence=3>. Acesso em 12/06/2017.

COUTINHO, Ana Luísa Celino. Direito Comparado e Globalização. Prim@ facie, João Pessoa, ano 2, n. 3, p. 30-41, jul./dez. 2003. Disponível em <http://www.ccj.ufpb.br/primafacie>. Acesso em 19/06/2017.

DELMAS-MARTY, Mireille. Três desafios para um direito mundial. Tradução Fauzi Hassan Choukr. Rio de Janeiro. Lumen Juris. 2003. 
DUARTE, Rui Pinto. Uma introdução ao direito comparado. Revista "O Direito $I V$ ”, Almedina, 2006, p. 769-792. Disponível em <http://rpdadvogados.pt/wp-content/uploads/bskpdf-manager/30_DIREITOCOMPARADO2006.PDF>. Acesso em: 08/06/2017.

GIACOMOLLI, Nereu José; VASCONCELLOS, Vinícius Gomes de. Justiça criminal negocial: crítica à fragilização da jurisdição penal em um cenário de expansão dos espaços de consenso no processo penal. Novos estudos jurídicos - Eletrônica. Vol. 20. $\mathrm{n}^{\mathrm{o}} 3$. Set/Dez 2015. $\quad$ p. $\quad 1108-1134 . \quad$ Disponível em <http://siaiap32.univali.br/seer/index.php/nej/article/view/8392>. Acesso em 22/06/2017.

GIVATI, Yehonatan. The comparative law and economics of plea bargaining: Theory and evidence. Harvard Law School. John M. Olin Center for Law, Economics, and Business Fellows' Discussion Paper Series. Discussion paper $n^{0}$ 39. p. 1-26 Cambridge. 07/2011. Disponível em <http://www.law.harvard.edu/programs/olin_center/fellows_papers/pdf/Givati_39.pdf>. Acesso em 19/06/2017.

GODOY, Arnaldo Sampaio de Moraes. Notas introdutórias ao direito comparado. Jus Navigandi, Teresina, ano 13, n. 1649, 6 jan. 2008. Disponível em: <https://jus.com.br/artigos/10824>. Acesso em: 9 jun. 2017.

GORDILHO, Heron Santana. Justiça penal consensual e as garantias constitucionais no sistema criminal do Brasil e dos EUA. Anais do XVIII Congresso Nacional do CONPEDI, São Paulo, 2009. Disponível em <http://www.publicadireito.com.br/conpedi/manaus/arquivos/anais/sao_paulo/2187.pdf>. Acesso em 23/06/2017.

MARTINS, Paulo Henrique; SIQUEIRA, Dirceu Pereira. A incorporação do modelo de precedentes vinculantes no Brasil como forma de jurisprudência defensiva dos tribunais e que se distingue da natureza dos "precedents" do "common law". Processo, jurisdição e efetividade da justiça I [Recurso eletrônico on-line] organização CONPEDI/UNICURITIBA; Coordenadores: Janaína Rigo Santin, Sérgio Henriques Zandona Freitas - Florianópolis: 
$\begin{array}{llllll}\text { CONPEDI, } & 2016 . & \text { p. } & 299-318 . & \text { Disponível } & \text { em }\end{array}$

<http://www.conpedi.org.br/publicacoes/02q8agmu/f2931cc7/PNrbFpE8V26NRF8K.pdf>.

Acesso em 21/06/2017.

MENDONÇA, Fabiano A. de S. Direito comparado: objeto do direito. FARN, Natal, v.l, n.l, p. 185 - 198 Jul./dez. 2001. p. 185-197. Disponível em <http://www.revistaunirn.inf.br/revistaunirn/index.php/revistaunirn/article/viewFile/32/35>. Acesso em 09/06/2017.

MESSITTE, Petter J. Plea bargaining in various criminal justice systems. 11th Annual Conference on Legal and Policy Issues in the Americas. Uruguai. 2010. Disponível em <https://www.law.ufl.edu/_pdf/academics/centers/cgr/11th_conference/Peter_Messitte_Plea_ Bargaining.pdf> . Acesso em 19/06/2017.

PESSOA, Flávia Moreira Guimarães. Manual de metodologia do trabalho científico: Como fazer uma pesquisa de direito comparado. Aracaju. Evocati. 2009.

ROCHA, Osiris. Porque aplicar direito estrangeiro. Revista da faculdade de direito. Universidade de Minas Gerais. Belo Horizonte. 1964. Disponível em <https://www.direito.ufmg.br/revista/index.php/revista/article/viewFile/369/341>. Acesso $12 / 06 / 2017$.

SÁNCHEZ, Jésus-Maria Silva. A expansão do direito penal: Aspectos da política criminal nas sociedades pós-industriais. Tradução: Luiz Otávio de Oliveira Rocha. São Paulo. Revista dos tribunais. 2002.

SIQUEIRA, Julio P. F. H. de. Natureza jurídica do Direito Comparado. Jus Navigandi, Teresina, ano 18, n. 3508, 7 fev. 2013. Disponível em: <https://jus.com.br/artigos/23674>. Acesso em: 9 jun. 2017.

SOUSA, Marcos Paulo Dutra. Colaboração (delação) premiada. Salvador. JusPODIVM, 2016.

Rev. de Pesquisa e Educação Jurídica | e-ISSN: 2525-9636| Maranhão | v. 3 | n. 1 | p. 57 - 74 | Jul/Dez. 2017. 
VARELLA, Marcelo D. Internacionalização do direito: Direito internacional, globalização e complexidade. 2012. 606 f. Tese (Livre-Docência em direito internacional) - Faculdade de Direito, Universidade de São Paulo, 2012. Disponível em 